DOI: https://doi.org/10.30749/2177-8337.v24n49p13-32

\title{
LEGISLAÇÕES SOBRE ABORTO E O DIREITO À SAÚDE DA MULHER
}

\section{LEGISLATION ON ABORTION AND WOMEN'S RIGHT TO HEALTH}

Reis Friede*

Resumo: 0 presente artigo busca apresentar uma reflexão sobre o aborto, a partir de uma breve retrospectiva dos diferentes métodos de abortamento utilizados ao longo do tempo, e levantar o que era, e é, considerado o marco inicial da vida humana. Também irá abordar os países que seguem leis restritivas sobre o tema e qual a relação dessas restrições sobre a saúde da mulher. A abordagem metodológica empregada na pesquisa foi a qualitativa, tendo sido feita uma pesquisa bibliográfica que levantou artigos acadêmicos e documentos que tratem do tema abordado. O material selecionado foi lido por uma perspectiva crítico analítica.

Palavras-chave: Legislação sobre aborto. Direitos Humanos. Saúde da Mulher.

Abstract: The present article seeks to present a reflection on abortion, from a brief retrospective of the different abortion methods used over time, and to raise what was, and is, considered the initial milestone of human life. It will also address countries that follow restrictive laws on the topic and the relationship of these restrictions to women's health. The methodological approach used in the research was qualitative, and a bibliographic research that raised academic articles and documents dealing with the theme addressed was carried out. The selected material was read from an analytical critical perspective.

Keywords: Abortion legislation. Human Rights. Women's Health.

Recebido em: 07/10/2020. Aceito em: 19/10/2020.

\footnotetext{
* Desembargador Federal, Mestre e Doutor em Direito, é Professor e Pesquisador do Programa de Mestrado em Desenvolvimento Local do Centro Universitário Augusto Motta (UNISUAM). E-mail: assessoriareisfriede@hotmail.com.
} 


\section{INTRODUÇÃO}

Em entrevista concedida em 2019, o Vice-Presidente Hamilton Mourão declarou que o aborto deve ser uma decisão da mulher. E foi além, ao afirmar que essa questão deve ser muito bem discutida, porque uma gravidez pode tanto decorrer de estupro ou em função de essa pessoa não ter condições de manter o filho, nos dando a entender que estes dois diferentes motivos seriam aceitos como razoáveis para a realização de um aborto. Declarações polêmicas, num primeiro momento, mas que já demonstram como o tema também divide a sociedade.

Muitos se perguntam porque as mulheres ainda precisam lidar com uma gravidez não planejada, e até mesmo indesejada, quando existem diferentes formas de se controlar a fertilidade. Uma resposta plausível seria que isso ocorre porque 0 acesso a informações confiáveis sobre métodos contraceptivos não é uma realidade na vida de todas as mulheres, que acabam recorrendo muitas vezes a um controle da natalidade ineficaz, sem contar que nenhum método contraceptivo pode ser considerado $100 \%$ seguro. Além disso, nem toda relação sexual ocorre de forma voluntária e desejada.

Diante desta realidade, a proposta deste artigo é fazer uma reflexão sobre o aborto, a partir de uma breve retrospectiva dos diferentes métodos de abortamento utilizados ao longo do tempo e levantar o que era, e é, considerado o marco inicial da vida humana. Também irá abordar os países que seguem leis restritivas sobre o tema e qual a relação dessas proibições sobre a saúde da mulher.

A abordagem metodológica empregada nesta pesquisa foi a qualitativa, tendo sido feita uma pesquisa bibliográfica que levantou artigos acadêmicos e documentos que tratem do tema abordado. 0 material selecionado foi lido por uma perspectiva crítico analítica.

\section{MÉTODOS DE ABORTAMENTO E O MARCO INICIAL DA VIDA}

A prática do aborto sempre esteve presente nas mais diferentes sociedades ao longo do tempo. Segundo Boltanski (2012), a prática do aborto voluntário não é 
tanto o que parece universal, mas sim o reconhecimento da possibilidade dessa prática, conforme as sociedades e conforme as épocas.

\begin{abstract}
Uma primeira propriedade, claramente afirmada por Devereux, é o caráter provavelmente universal dessa prática. Devereux indica que, no caso de cerca de $60 \%$ das sociedades registradas nos Area files, encontram-se informações sobre o aborto. Isso não significa, é claro, que o aborto seja desconhecido nas $40 \%$ restantes, mas apenas que, dado o caráter bastante heterogêneo da informação contida nesses arquivos, nem sempre os etnógrafos levaram em conta essa dimensão da existência em suas monografias ou seus informantes não falaram sobre isso. (BOLTANSKI, 2012, p. 208).
\end{abstract}

As formas utilizadas pelas mulheres para realizar um aborto são as mais diversas, mas envolvem basicamente a ingestão de alguma substância para provocalo (chás, medicamentos, poções, alimentos, etc.) ou o uso de algum procedimento físico interno ou externo (introduzir um objeto que chegue até o útero, apertar a barriga para expulsar o feto, aplicar algum tipo de unguento quente/frio, etc.), e até mesmo a combinação dessas duas formas. Mas também é possível o emprego de um meio mágico:

Tais métodos, químicos ou mecânicos, têm correlação com cada uma das teorias locais referentes à reprodução e à gestação, sobre as quais repousa a confiança depositada em sua eficácia. São igualmente empregados meios mágicos (sentar-se sob determinada árvore, comer ou beber um certo alimento, carregar um amuleto, etc.). Esses meios mágicos, nitidamente distinguidos dos meios mecânicos ou químicos em geral, repousam muitas vezes na realização de um ato transgressivo (o alimento ingerido é proibido etc. (BOLTANSKI, 2012, p. 209).

Abortar tanto pode ser a interrupção natural de uma gravidez como também uma interrupção provocada, e essa ação faz parte das práticas sociais de diferentes grupos ao longo da história da humanidade. No Brasil, o ato de abortar é, em regra, considerado crime e, por isso, realizado de forma clandestina, na maioria dos casos, particularmente quando não permitido pela lei. Mas nem sempre essa prática foi vista por esta perspectiva ao longo do tempo e a leitura de diferentes autores, nas mais diversas áreas, demonstra como o abortamento era encarado entre os povos desde a Antiguidade.

A Constituição Federal (1988), no Capítulo I "DOS DIREITOS E DEVERES INDIVIDUAIS E COLETIVOS", Art. 50, garante que "Todos são iguais perante a lei, sem distinção de qualquer natureza, garantindo-se aos brasileiros e aos estrangeiros 
residentes no País a inviolabilidade do direito à vida, à liberdade, à igualdade, à segurança e à propriedade" (BRASIL, 1988). Analisando este parágrafo podemos entender que o indivíduo tem assegurado tanto o direito de continuar vivo quanto o direito de viver uma vida digna; logo, para que esses direitos sejam garantidos, é preciso entender o significado do que é vida.

Se o aborto está no oposto da vida, o que é vida? Segundo o dicionário Aulete Digital (2020), o conceito VIDA possui 18 definições, dentre as quais se destacam, com especial ênfase, aquelas que se encontram relacionadas, direta ou indiretamente, à temática abordada aqui.

(vi.da)

sf.

1. Biol. Condição da existência de alguns seres como os homens, animais e outros organismos, marcada por nascimento, desenvolvimento, envelhecimento e morte; EXISTÊNCIA [Antôn.: morte.]

2. Estado de quem está vivo.

3. Duração desse estado (vida longa); EXISTÊNCIA (...)

4. $O$ fato de viver.

5. Conjunto das condições, sobretudo materiais, necessárias à preservação da existência. [F.: Do lat. vita.]. (AULETE DIGITAL, 2020).

O conceito de vida define, geralmente, o período de existência de um ser vivo desde o momento que nasce até sua morte. Mas definir o que é vida não é tão simples. Para alguns, existe vida desde a concepção, contrariando assim uma definição biológica; numa outra perspectiva, se vida está relacionada à ação, ainda assim podemos considerar como vivente quem não esteja ativo.

A sempre renovada discussão referente ao momento no qual o embrião
humano passa a "merecer" respeito à sua vida e integridade, apenas
comprova a aleatoriedade e o caráter pragmático da caracterização do início
da vida. Esta observação encontra esteio, por semelhança, na recente
mudança do conceito de morte, quando a morte encefálica, por motivação
essencialmente utilitária, foi identificada com morte.
Assim como o desenvolvimento das técnicas de transplantes de órgãos vitais,
a partir de doadores "mortos", passou a exigir a redefinição do momento de
morte, para que esses fossem viáveis, o desenvolvimento das técnicas de
reprodução assistida está estimulando um questionamento do momento de
início da vida, para que, pelo destino que não se sabe qual dar aos embriões
excedentes, este outro avanço científico (a reprodução assistida) não seja
obstaculizado. (SEGRE, 2004, p. 257).

Algumas das teorias científicas já elaboradas sobre o início da vida sugerem que ela: a) se inicia com a fecundação; b) se inicia com a nidação (momento em que o óvulo fixa-se na parede do útero); c) se inicia com o surgimento da atividade 
cerebral. Mas a sociedade, de maneira geral, não se posiciona pela ótica científica, o mais natural é um posicionamento pela visão religiosa ou do senso comum, o que explica o fato de nenhum argumento minimamente lógico conseguir dar conta de explicar o posicionamento contrário ao aborto que não seja com invocações morais e religiosas.

A liberdade garantida constitucionalmente de crença, de religião e de decisão não fica em risco caso a descriminalização e, quem sabe, liberação do aborto venha a ocorrer no Brasil. Cada mulher deve ser livre para poder decidir o que the for mais adequado quando da existência de uma gravidez programa ou não, desejada ou não, e cada mulher também deve ter consciência de que somente ela pode arcar com a responsabilidade moral diante de suas escolhas perante a sociedade, Deus e, principalmente, com sua consciência.

A prática do aborto ocorre por meio de diferentes métodos, sejam eles físicos ou medicamentosos, incluindo aqui o uso de chás de ervas, e sua prática ocupa um lugar de debates nos diferentes campos que compõem a sociedade: religioso, ético, jurídico, moral, etc. Assim como tantas outras práticas sociais, a forma como cada grupo vai lidar com ela vai diferir ao longo do tempo. Em alguns momentos pode ser encarado como algo natural, como uma forma da mulher se libertar das consequências de uma gravidez que possa Ihe trazer complicações na vida social quando, por exemplo, ela fica grávida de outro homem que não seu marido. Ou quando ela é solteira. Em outros períodos, em outras culturas, a prática é vista como um crime grave contra a vida, e tanto quem pratica quanto quem auxilia nessa prática podem ser condenados a duras penas.

\footnotetext{
Muitas das convicções que hoje são dados adquiridos constituem, na verdade, o fruto de um árduo trabalho amadurecido ao longo dos séculos: o papel da mulher, as formas de considerar o feto e a gravidez, as intervenções externas, os interesses políticos e os parâmetros de avaliação mudaram desde a Antiguidade até os dias de hoje, assumindo diferentes funções e significados. (GALEOTTI, 2007, p. 21).
}

Uma referência antiga sobre práticas abortivas menciona que "entre 2.737 e 2.696 a.C., o imperador chinês Shen Nung cita, em texto médico, a receita de um abortífero oral, provavelmente contendo mercúrio". (SCHOR; ALVARENGA, 1994, p. 15). 
A grande questão centralizadora das discussões sobre a legalidade ou não do aborto encontra-se, entretanto, relacionada ao início da vida, ou seja, a partir de que momento a vida começa? Por ser, até então, uma pergunta sem resposta, ou com respostas múltiplas, não é possível esperar uma solução que atenda aos anseios de toda a sociedade.

Hoje, com o avanço da luta por direitos iguais e um maior protagonismo feminino, a discussão que se coloca perpassa tanto pelo fato da mulher ser a única a ter o direito de decisão porque "o corpo é dela", como também pela justificativa de que, dependendo da situação, é ela quem vai ter que arcar com toda a responsabilidade sobre uma criança, em casos específicos, e, por isso, somente ela quem deve decidir. Mas ao longo da história podemos ver que nem sempre o aborto foi um assunto pertencente preponderantemente ao universo feminino.

Jacobsen (2009), em resenha sobre o livro de Giulia Galeotti (2007), nos lembra que tanto o papel que se atribui à mulher no espaço social, quanto a forma de se conceber o feto e a gravidez, bem como interesses políticos, vêm delineando decisiva e diversamente a história do aborto desde a Antiguidade.

Segundo Marques e Bastos (1998) e Schor e Alvarenga (1994), a prática do aborto é antiga e conhecida em todas as épocas e culturas, tendo um sentido e significado específico em cada uma delas. sobre isto, Pattis (2000) acrescenta que o aborto foi exercido por todos os grupos humanos até hoje conhecidos, embora possuam concepções, motivações e técnicas completamente diferentes ao longo do tempo. (REBOUÇAS, 2010, p. 11-12).

O século XVIII seria um marco divisor na história do aborto a partir dos descobrimentos médicos e das formações dos Estados nacionais, quando a vida do feto passou a ser privilegiada por poder vir a ser um futuro soldado ou trabalhador e, com isso, fez com que o homem passasse a opinar sobre ele. Antes disso, por ser a mulher a única que podia testemunhar sobre sua gravidez, o aborto era fundamentalmente uma questão feminina. (JACOBSEN, 2009).

[...] eram as mulheres aquelas que dirigiam conselhos e instruções às gestantes; eram elas que ajudavam a parir e a abortar. Ademais, cabia exclusivamente à mulher grávida anunciar seu estado. Uma mulher que não houvesse comunicado sua gravidez também não poderia ser acusada de haver abortado. Em outras palavras, aborto era uma questão de mulheres, 0 que não significa que 0 fruto do nascimento fosse social, econômica e politicamente irrelevante. (JACOBSEN, 2009). 
Em 1960 ocorreu uma revolução com relação ao controle de natalidade, quando o Food and Drug Administration - FDA, agência federal do Departamento de Saúde e Serviços Humanos dos Estados Unidos, que é o órgão americano que controla a liberação de medicamentos para uso, aprovou a venda do Enovid como o primeiro anticoncepcional oral do mundo. Mais do que permitir que as mulheres passassem a ter controle sobre sua fertilidade, o medicamento também veio a causar uma maior liberdade feminina no campo da sexualidade. Já vivíamos em uma época na qual o poder sobre o feto, ao contrário de tempos mais pretéritos, estava nas mãos do homem e da sociedade. Mas mesmo com o uso de diferentes métodos contraceptivos, muitas vezes uma gravidez não planejada ainda acaba acontecendo.

Uma reportagem da BBC News, usando análise de dados do Google, mostra que pesquisas por pílulas abortivas na internet dobraram no mundo durante a última década. Os dados mostram como a tecnologia está ajudando as mulheres a burlar as barreiras legais ao aborto ao terem acesso a esse medicamento online. Mais conhecido como Cytotec, o Misoprostol combinado ao Mifeprostone provoca o que se conhece como aborto medicamentoso. (BBC NEWS, 2018).

Enquanto mulheres em países como o Reino Unido podem ter os remédios receitados por um médico, mulheres que compram as pílulas pela internet em países onde a legislação é restritiva estão frequentemente violando a lei e correndo o risco de sofrer grandes punições, além de incorrer em riscos à saúde. (BBC NEWS, 2018). 
Diagrama 1 - Procura por pílulas abortivas por país.

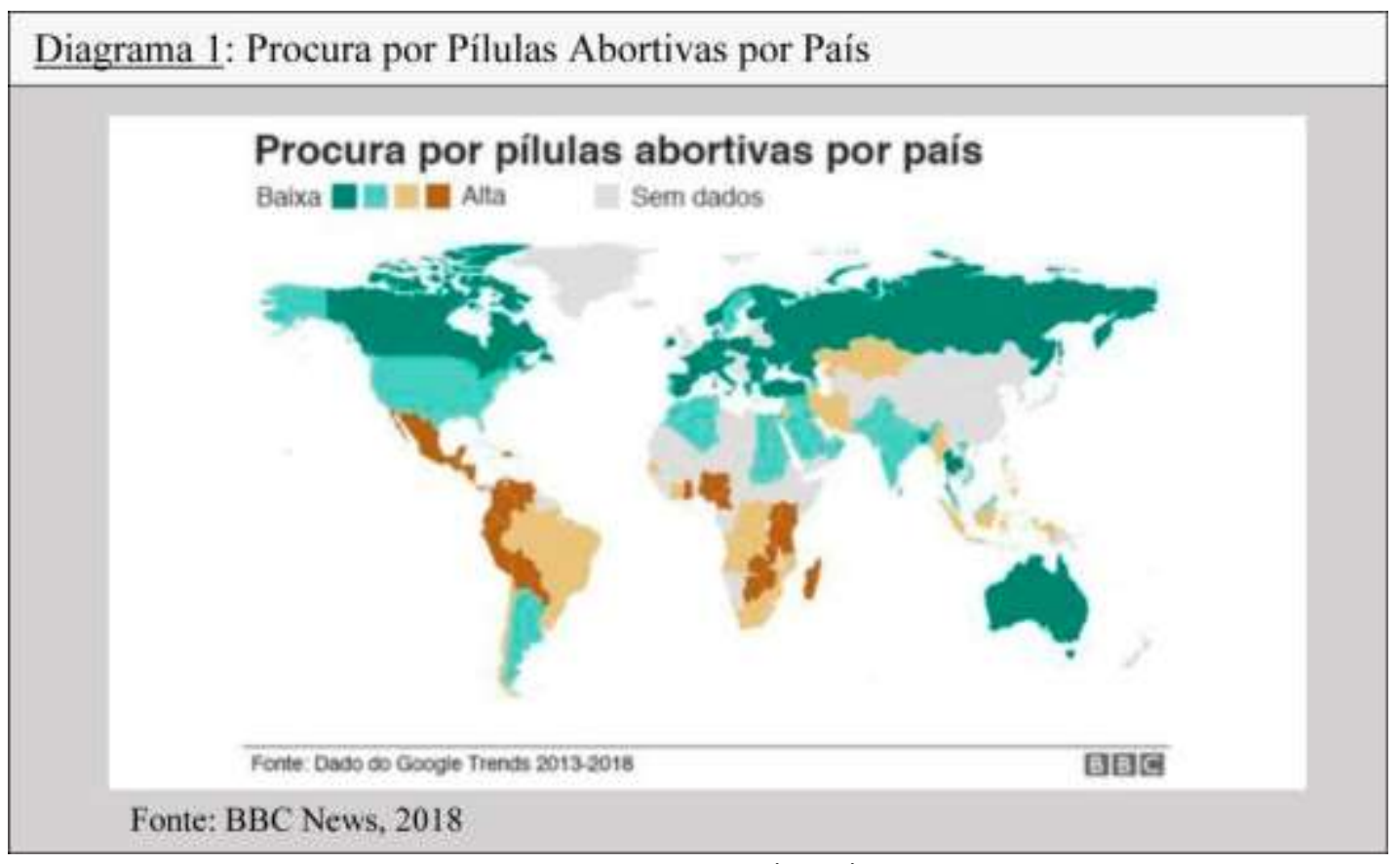

Fonte: BBC News (2018).

Pelos dados disponíveis é forçoso reconhecer que países que têm legislação restritiva sobre o aborto, como também forte influência religiosa na vida da população, costumes mais tradicionais e grandes diferenças econômicas, apresentam maiores índices (logicamente) de busca pelo medicamento. Poderíamos até mesmo imaginar que estes índices mais altos ocorram em países cuja educação básica não atinja a população de forma igualitária, e até mesmo com baixos índices no PISAPrograma Internacional de Avaliação de Alunos, uma avaliação internacional que mede o nível educacional de jovens de 15 anos por meio de provas de Leitura, Matemática e Ciências (caso a avaliação seja aplicada).

É importante registrar que o aborto não era considerado como delito quando a sociedade entendia que $\mathrm{o}$ feto era propriedade da gestante, praticamente um apêndice de seu corpo, e por isso cabia a ela decidir se continuava, ou não, com a gravidez. O Código de Hamurabi fazia referência ao aborto, mas não aquele provocado pela gestante, e sim o aborto que a ela era imputado. Quem fizesse uma mulher abortar poderia pagar uma pena em dinheiro ou com a própria vida, e como a mulher era uma propriedade do marido, este que era considerado o maior prejudicado. (SÁ, 2016). 
Segundo Matielo (1996), Aristóteles via na prática do aborto uma forma eficaz de se manter o nível populacional estável nas cidades gregas. Já no período da República Romana (509 a.C. - 27 a.C.), ainda que fosse vista como imoral, a prática do aborto era amplamente utilizada pelas mulheres que o faziam pela ingestão de preparados medicamentosos, ou venenosos, dependendo do ponto de vista. Por conta do uso indiscriminado de substâncias que tanto poderiam ser usadas para curar como para matar, e diante dos altos números de mortes por possíveis envenenamentos, uma lei foi criada para punir estes atos, a lex Cornelia de venefici, cujo texto pode ser traduzido da seguinte forma:

\begin{abstract}
O pretor ou o presidente do tribunal do júri, a quem pela sorte é cabida a quaestio de veneficis sobre o crime, que na cidade de Roma ou até de uma milha dela tenha sido cometido (tivera sido cometido), deve junto com os jurados, que foram sorteados segundo essa lei, instaurar um processo capital contra aquela pessoa, que prepara ou preparou um veneno com a intenção de matar, vender, comprar, portar consigo, prescrever. (HÖBENREICH, 2003, p. 29).
\end{abstract}

Como os abortos eram provocados pela ingestão de preparados, exceto por algumas substâncias que realmente eram venenosas, outras composições somente seriam usadas para matar se realmente existisse essa intenção. Sendo assim, a Lei Cornelia poderia ser usada para punir toda mulher casada que abortasse, bem como a pessoa que praticasse o aborto. Mas ainda que existisse a lei, sua aplicação ocorria só porque se entendia que essa prática era uma ofensa ao marido, prejudicado por perder a futura prole, e não para se preservar a vida do feto. "O aborto não levantava problemas éticos e o direito era influenciado pela tese estoica do feto como pars viscerum matris ("parte das entranhas maternas")". (SÁ, 2016).

Foi com a adoção do cristianismo e com a agregação de seus valores pelas sociedades que o adotaram (a romana inclusa), que inseriu-se a concepção que trazemos até hoje, de que o embrião/feto é uma vida e tem seu direito resguardado desde o momento de sua concepção. Como bem coloca Matielo, "Além do mais, sendo o homem criado à imagem e semelhança de Deus, não deveria, então, ter o poder de vida e morte sobre os demais, atributo este exclusivamente do Criador". (MATIELO, 1996, p. 15).

No período medieval a condenação ao aborto não seguia uma mesma regra, variando muito de lugar a lugar. Tinham lugares com sanções severas, outros com 
mais brandas e lugares que nem mesmo uma regulamentação existia, ficando a cargo dos costumes locais o julgamento dessa prática. (SÁ, 2016).

Em face do poder exercido pela Igreja, que trazia consigo um direito canônico extremamente repressivo e punitivo ao aborto, as nações que eram mais submissas às suas ideias - o que envolvia aspectos não apenas ideológicos, mas econômicos e militares - puniam tal prática mais severamente, enquanto as que não eram tão influenciadas tendiam de uma forma geral a serem mais brandas no tratamento a esta questão. (SÁ, 2016).

Desta feita, é cediço concluir que somente após a Revolução Francesa, e já no século XVIII, - centúria esta considerada como um marco divisor na história do aborto - é que as questões relacionadas ao tema passaram a ser vistas de forma mais homogênea. Após a lei inglesa de 1803, que passou a punir a prática de forma severa, a situação jurídica vai se processar através de uma "virada radical", com diferentes países adotando esta lei como modelo na Europa e também nos Estados Unidos. Mas uma justificativa para que isso ocorresse foi concedida por Mori (1997) nos seguintes termos:

\footnotetext{
Nas primeiras décadas do século XIX, notou-se que qualquer intervenção cirúrgica (inclusive o aborto) era muito arriscada e frequentemente fatal para as pacientes. Graças a essa observação clínica proibiu-se, portanto, o aborto, assim como todas as outras intervenções cirúrgicas, a fim de proteger a vida das mulheres. (MORI, 1997, p. 19).
}

Nesse sentido, o combate ao aborto passa a ser uma medida preventiva para se poupar a vida da gestante, e não por haver uma preocupação com o feto. Não havia tecnologia suficiente na época que permitisse que a intervenção fosse feita de forma a não provocar a morte da paciente.

E a Igreja Católica, detentora de grande influência sobre as decisões que afetam a vida em sociedade, como vemos acontecer ainda hoje, continuava exercendo seu poder de controle e repressão às ideias que preconizassem a liberação da prática do aborto. Como também outras instituições sociais. Se ao longo da história vimos religiosos cristãos que não condenavam o aborto e até mesmo entendiam que a vida humana somente começava a partir de um determinado período quando o feto recebia uma alma, em 1869 o catolicismo aboliu a distinção 
entre feto com alma e feto sem alma, ou seja, o aborto passou a ser algo universalmente condenado.

\section{PROIbições aO ABORto Pelo mundo e a segurança da saúde FEMININA}

O Brasil está naquele momento em que muitos países que liberaram a prática do aborto, ou a descriminalizaram, já passou. Qual o caminho que queremos seguir: o da proibição total ou o da liberação total?

Queremos ir na direção de Malta, o país da União Europeia (UE) com a lei mais restritiva sobre o aborto, onde a interrupção da gravidez é proibida sem nenhuma exceção, considerado um dos mais misóginos do mundo, onde o movimento Gift of Life (Dom da Vida) pretende erigir à preceito constitucional a proibição do aborto, onde o divórcio é proibido e a vida pública é condicionada pela religião de Estado? Ou queremos ir na direção da Holanda, o país dos antípodas europeus dos malteses, onde a decisão sobre a interrupção voluntária da gravidez é tomada pela gestante? (TORRES, 2012, p. 40).

Da $12^{\mathrm{a}}$ semana de gestação na Alemanha até a $22^{\mathrm{a}}$ semana de gestação na Holanda, ao todo são 63 países onde o aborto é considerado uma prática legal, sem qualquer ônus penal sobre quem o pratica, sendo a Rússia o primeiro país no mundo a legalizar o aborto em 1920. A legislação sobre o aborto, em todo o mundo, vai desde a proibição total até a liberação total, sendo muito mais comum leis que fiquem entre esses dois extremos, ou seja, que permitem que o aborto seja praticado em alguns casos específicos, como ocorre, ainda, no Brasil.

Países devem "agir agora" para descriminalizar o aborto, cobraram especialistas de direitos humanos das Nações Unidas. Relatores alertaram que abortos inseguros matam 47 mil mulheres por ano em todo o mundo. Quando não resulta em morte, a prática causa sequelas severas -5 milhões de mulheres têm alguma forma de deficiência permanente ou temporária provocada por tentativas de interromper a gravidez. (NAÇÕES UNIDAS BRASIL, 2018).

Mas em quais países a prática ainda é proibida e, principalmente, totalmente criminalizada? Em cinco países o aborto ainda tem proibição total: Vaticano, Malta, Nicarágua, El Salvador e República Dominicana, ou seja, o aborto é proibido em qualquer hipótese podendo ir para a prisão tanto quem o praticou quanto quem ajudou. Em contraponto, no Canadá e na Holanda, por exemplo, ele é totalmente livre, sendo a decisão final de fazê-lo ou não tomada pela própria gestante. 
O Vaticano, que é uma cidade-estado, é o menor país soberano no mundo. Localizado na Itália e cercado pela cidade de Roma, é a sede da Igreja Católica Romana e também a residência do Papa, que é a autoridade máxima da Igreja e chefe de Estado, governando cerca de 900 pessoas.

Loomis (2008, p. 89), citado por Silva (2000), sobre a origem da proibição ao aborto na concepção católica, afirma que "Em 1869, a Igreja Católica se manifestou contra todos os abortos a pedido de Napoleão III da França, onde a população estava em declínio. O Papa Pio IX declarou que a vida começa na concepção tendo que ser protegida depois disso", defendendo que o ser humano existe desde o momento da fecundação.

\begin{abstract}
Talvez a primeira razão para se evitar buscar a verdade sobre o início da vida seja a absoluta falta de consenso sobre o tema. Nem mesmo na história cristã se encontra consenso. A posição atual da Igreja Católica - e da vasta maioria das igrejas protestantes - de que a vida começa na concepção só foi pacificada em 1869 por Pio IX. Na Idade Média, alguns cristãos defendiam uma lógica próxima da lógica de estoicos e judeus, acreditando na pneuma, ou seja, que a vida começa quando o ar enche os pulmões pela primeira vez. SANTO AGOSTINHO e SÃO TOMÁS DE AQUINO acreditavam que o feto ganhava alma em torno do quadragésimo dia após a concepção. (SILVA, 2000, p. 301-302).
\end{abstract}

Durante sua existência, a Igreja Católica sempre se apresentou oscilante entre o início da vida. Hoje, o Vaticano, na figura de seu governante, o Papa, continua com a política antiabortiva. Em junho de 2018 o Papa Francisco criticou a aprovação do aborto em seu país natal, Argentina, comparando essa "moda" ao que os nazistas faziam. Ainda afirmou que "no século passado, todo mundo se escandalizava com o que os nazistas faziam pela pureza da raça", porém, "hoje fazemos o mesmo com as luvas brancas". (ACI DIGITAL, 2018).

\begin{abstract}
Nenhum ser humano jamais pode ser incompatível com a vida, seja pela sua idade, pela sua saúde e pela qualidade da sua existência. Toda criança, desde o seio da sua mãe, é um dom, que muda a história de uma família. Ela deve ser sempre bem-vinda, amada e cuidada", disse o Papa FRANCISCO durante o Encontro Internacional "Sim à vida: cuidado com o precioso dom da vida na fragilidade". (CNBB, 2019).
\end{abstract}

O arquipélago de Malta, que faz parte da União Europeia, está localizado no Mar Mediterrâneo e é composto por cinco ilhas, sendo apenas três delas habitadas: Malta, Comino e Gozo. É uma república democrática parlamentar, tendo como chefe de governo o Primeiro-Ministro e como chefe de Estado o Presidente, cujo papel é 
principalmente representativo. Sua população era, em 2018, de 408.712 habitantes, sendo $98,2 \%$ católicos.

Malta encara o aborto como uma questão criminal, o que pode fazer crer que isso está relacionado ao fato de sua população ser predominantemente católica e que isso levaria o país a sustentar um certo conservadorismo, mas de forma controversa ao que se pode imaginar, em julho de 2017 o parlamento aprovou o casamento entre pessoas do mesmo sexo. Em contrapartida, o aborto é considerado ilegal em qualquer circunstância, mesmo que a vida da gestante esteja em risco, a pílula do dia seguinte não pode ser comercializada e anticoncepcional só é vendido com receita médica.

A República de Nicarágua é um país presidencialista localizado na América Central, que contava, em 2018, com 6,218 milhões de habitantes e como religião predominante o catolicismo. Na Nicarágua o aborto é proibido em qualquer circunstância, mesmo que a mãe corra risco de vida, como relatado abaixo:

\begin{abstract}
Uma lei "pró-vida" está matando mulheres na Nicarágua. Ela matou Amelia, 27, doente com câncer que não pôde ser tratado a tempo. Ela estava com dez semanas de gravidez e o câncer havia atingido seu cérebro, pulmão e mama, mas no hospital lhe foi negado o tratamento quimioterápico "dada a grande possibilidade de que isso causasse um aborto". Quando as autoridades concordaram com o tratamento, Amelia já estava no primeiro trimestre da gravidez. O bebê morreu aos oito meses de gestação e ela meses depois. (CERDA, 2018).
\end{abstract}

Até 2006 o Código Penal nicaraguense despenalizava a prática do aborto quando uma junta médica avaliava a situação da gestante e indicava o procedimento. Após 2006 o novo Código Penal passou a proibi-lo completamente, inclusive em casos de estupro, risco de vida para a gestante e inviabilidade do feto, passando a penalização para até dois anos de prisão para as mulheres e até seis anos aos profissionais que pratiquem o aborto. Após essa mudança no Código Penal a Nicarágua passou a integrar a lista dos Estados independes que estabelecem a proibição total do aborto.

El Salvador é um país localizado na América Central, com território limitado por Honduras (a leste), Guatemala (a noroeste) e o oceano Pacífico (ao sul e a leste). Sua organização política é republicana, democrática e representativa. Sua população soma 6.200.781 habitantes, sendo formada por mestiços de índios e espanhóis, com 
mais da metade da população vivendo em condições de pobreza. A religião predominante é a católica.

Segundo dados da Anistia Internacional, "El Salvador tem uma das leis sobre aborto mais restritivas do mundo. $\mathrm{O}$ aborto é totalmente proibido em todas as circunstâncias, e as mulheres acusadas de pôr fim a uma gravidez se arriscam a duras condenações" (ANISTIA INTERNACIONAL, 2015), podendo cumprir até a cinquenta anos de prisão.

Em 1998 o Código Penal foi modificado e o aborto, que antes era permitido em casos de estupro, risco de vida para a gestante e inviabilidade do feto, passou a ser considerado crime de homicídio, punindo também os possíveis cúmplices, como médicos, enfermeiros e farmacêuticos, que, quando denunciados, podem ser condenados a até doze anos de prisão. Isso faz com que as mulheres sejam imediatamente denunciadas quando dão entrada nos hospitais, para evitar que estes profissionais possam ser envolvidos, ainda que o aborto seja espontâneo.

A situação é tão alarmante que foi elaborado um relatório, intitulado $\dot{A}$ beira da morte: a violência contra a mulher e a proibição do aborto em El Salvador, que descreve como estas leis restritivas estão destruindo as vidas das mulheres e meninas.

\begin{abstract}
No mês passado, em El Salvador, uma jovem mulher foi libertada após quase uma década atrás das grades. Carmen Guadalupe Vásquez Aldana tinha apenas 18 anos, em 2008, quando foi condenada a 30 anos de prisão. O seu crime? Um aborto espontâneo.

El Salvador tem uma das leis mais draconianas de aborto do mundo. Ele é criminalizado em todos os aspectos, inclusive quando a vida ou saúde da mãe está em perigo, além de casos de estupro. Meninas e mulheres não tem acesso ao aborto mesmo com uma gravidez de risco, ou mesmo quando os fetos não são saudáveis.

Aquelas que desafiam a lei e procuram por abortos clandestinos e inseguros enfrentam consequências terríveis: a Organização Mundial da Saúde, em 2008, divulgou que 9\% das mortes maternas na América Central ocorrem devido a esses procedimentos. (ROSAS, 2015).
\end{abstract}

Na República Dominicana o aborto é totalmente proibido e criminalizado. 0 país, que está localizado na América Central, contava com uma população de 10.090.151 habitantes em 2018, sendo, em sua maioria, católicos.

Em 2010 a Constituição passou por uma reforma que garante o direito pleno à vida, sendo este direito considerado inviolável desde o momento da concepção até a morte. 0 Código Penal dominicano criminaliza todas as formas de aborto, prevendo 
pena de até vinte anos para os profissionais de saúde e de até dois anos para as mulheres que praticarem o aborto.

\begin{abstract}
Na República Dominicana o aborto é ilegal em todas as circunstâncias, inclusive quando está em risco a vida da mulher ou menina grávida. A proibição total do aborto no país tem consequências devastadoras. As mulheres e meninas grávidas de modo não planejado ou não desejado incluindo os casos de estupro, ou incesto, ou nos casos de inviabilidade da vida do feto - se veem obrigadas a escolher entre um aborto clandestino ou seguir adiante com a gravidez, ainda que não deseje ou que implique em graves riscos para sua saúde, incluindo a morte. Algumas mulheres e meninas contam com recursos e meios para viajar a outro país onde o aborto é legalizado ou encontram serviços de saúde seguros que thes ajudam a abortar, mas muitas, especialmente aquelas de comunidades pobres e rurais, arriscam sua saúde e sua vida, submetendo-se a abortos clandestinos, frequentemente sem orientação de alguém capacitado. Algumas mulheres e meninas sofrem graves problemas de saúde, ou até mesmo acabam morrendo, por causa de abortos inseguros. (HUMAN RIGHTS WATCH, 2018).
\end{abstract}

De acordo com os dados divulgados por um estudo conduzido pela Organização Mundial da Saúde (OMS), mais de 25 milhões de abortos inseguros (45\% do total) ocorrem anualmente no mundo, a maioria deles realizada em países da África, Ásia e América Latina. Segundo este estudo, a restrição ou proibição do acesso não reduz o número de abortos, e quando os abortos são praticados de acordo com as recomendações da OMS, o risco de complicações severas ou de morte é insignificante. (NAÇÕES UNIDAS BRASIL, 2017).

Nas pesquisas sobre o posicionamento em relação ao aborto nos cinco países relacionados acima, Vaticano, Malta, Nicarágua, El Salvador e República Dominicana, diversas notícias mostravam a morte da gestante como consequência não do aborto propriamente, mas da sua negação para que ela pudesse fazer o tratamento médico indicado quando era diagnosticada com alguma enfermidade, como câncer, por exemplo. Também é significativo o número de mulheres que engravidam após um estupro.

\footnotetext{
A temática da violência sexual vem sendo amplamente discutida em todo o mundo apesar de não ser uma problemática exclusiva da atualidade. Estudo realizado em 56 países estima que $1 \mathrm{em}$ cada 14 mulheres no mundo já sofreu violência sexual praticada por homens desconhecidos. De acordo com - Anuário Brasileiro de Segurança Pública, com dados de registros policiais realizados no ano de 2014, "[...] uma pessoa foi estuprada a cada 11 minutos". (LIMA; LAROCCA; NASCIMENTO, 2019, p. 418).
} 
O Artigo 22 da Declaração Universal dos Direitos Humanos afirma que direitos econômicos, sociais e culturais são garantias indispensáveis para a dignidade e o desenvolvimento do homem. "Para a ONU, saúde, educação, moradia e a gestão séria da justiça não são produtos à venda para poucos, mas em vez disso são direitos que todos devem ter, sem discriminação, disse Navi Pillay, ex-chefe de direitos humanos da ONU, na publicação The Tunis Imperative." (NAÇÕES UNIDAS BRASIL, 2017). Dentre esses direitos está a garantia de mulheres e meninas poderem requerer o acesso a serviços e cuidados de aborto e pós aborto com segurança e qualidade. Principalmente quando o direito ao aborto está garantido por lei, como é o caso da gravidez como consequência de violência sexual. Negar a uma mulher o direito de abortar quando ela engravida em consequência de um estupro é condená-la duas vezes.

\begin{abstract}
Descobrir-se grávida de um agressor é, sem dúvida, uma nova situação de violência. Além disso, a questão do abortamento é carregada de preconceitos e julgamentos morais por parte da sociedade e não raro pelas próprias mulheres violentadas que expressam se sentirem culpadas por não desejar levar adiante a gestação. Enfrentar seus próprios preceitos morais, expondo para profissionais da rede de atendimento o ocorrido, além dos sintomas gestacionais e, muitas vezes, da falta de suporte familiar, faz deste enfrentamento um longo e doloroso percurso. (LIMA; LAROCCA; NASCIMENTO, 2019, p. 418).
\end{abstract}

Em maio de 2018 a população da Irlanda foi consultada, por referendo, sobre a descriminalização do aborto no país, com $66,4 \%$ dos votos os irlandeses decidiram pelo sim. A lei antiaborto da Irlanda era uma das mais rigorosas do mundo. Com a aprovação do Parlamento, o país passa a integrar a maioria dos países europeus com leis que permitem a interrupção voluntária da gravidez. 
Diagrama 2 - As leis de aborto na Europa.

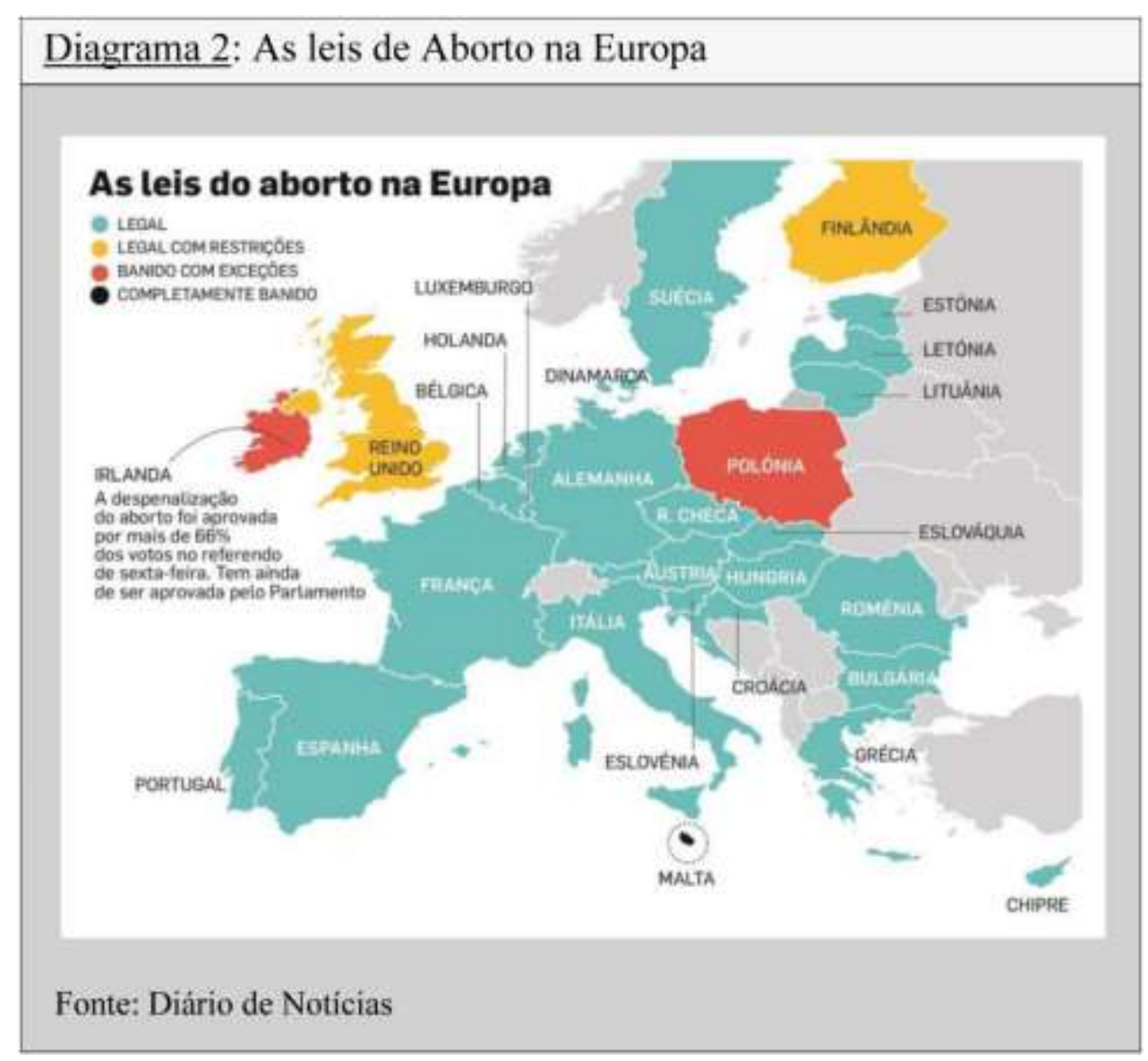

Fonte: Tecedeiro (2018).

A preocupação com a saúde da mulher é o principal motivo para se lutar pela legalização do aborto, mas muitos outros também estão envolvidos, como o direito da mulher de escolher quando engravidar, a liberdade da mulher de poder decidir não seguir adiante quando ocorre uma gravidez não planejada ou quando esta coloca sua vida em risco e, principalmente, o direito de interromper uma gravidez fruto de violência sexual.

\section{CONCLUSÕES}

O tema do aborto é muito caro em todas as sociedades, mesmo aquelas em que a prática está legalizada, pois o processo de legalização ocorreu a partir de muitas lutas das mulheres, apoiadas por grupos que entendem o aborto como uma necessidade em algumas situações. 
Com relação à legislação, em todo o mundo, vimos que em 63 países o aborto é considerado uma prática legal, sem qualquer ônus sobre quem o pratica, mas também vimos que em cinco países ele continua sendo considerado uma prática criminosa passível de prisão, ainda que tenha ocorrido de forma espontânea.

Temos desde países que praticam o aborto de forma totalmente livre, como uma política pública de governo, bastando a mulher buscar uma clínica especializada para que ele seja realizado sem qualquer tipo de interrogatório sobre os motivos que a levaram a essa decisão, até aqueles em que só permitem essa prática em alguns casos específicos, como ocorre, ainda, no Brasil. O mais comum é observamos leis que fiquem entre a liberação total e a proibição total.

Ainda que o aborto seja uma prática de difícil consenso sobre sua legalidade, uma consensualidade para definir o início da vida humana é ainda mais difícil, e é justamente essa dificuldade de definição que torna um posicionamento sobre o aborto mais complexo, o que torna a mulher que o pratica, e qualquer pessoa que a ajude, possíveis homicidas.

\section{REFERÊNCIAS}

ACI DIGITAL. Papa Francisco sobre o aborto: é o mesmo que faziam os nazistas, mas com luvas brancas. ACI Digital, Vaticano, 18 de jun. de 2018. Disponível em: https://www.acidigital.com/noticias/papa-francisco-sobre-o-aborto-e-o-mesmo-quefaziam-os-nazistas-mas-com-luvas-brancas-19184. Acesso em: 13 fev. 2019.

ANISTIA INTERNACIONAL. Doze fatos sobre a proibição do aborto em El Salvador. Anistia Internacional Brasil, [S. I.], 22 de abril de 2015. Disponível em: https://anistia.org.br/noticias/doze-fatos-sobre-proibicao-aborto-em-el-salvador/. Acesso em: 16 set. 2019.

AULETE DIGITAL. Vida. [S. I.], 2020. Disponível em: http://aulete.com.br/vida. Acesso em: 10 out. 2019.

BBC NEWS. Busca por aborto caseiro na internet dobrou na última década. BBC News, [S. I.], 07 jun. 2018. Disponível em: https://www.bbc.com/portuguese/brasil44389143. Acesso em: 11 fev. 2019.

BOLTANSKI, Luc. As dimensões antropológicas do aborto. Revista Brasileira de Ciência Política, Brasília, n. 7, p. 205-245, jan./abr. 2012.

BRASIL. [Constituição (1988)]. Constituição da República Federativa do Brasil de 1988. Brasília, DF: Presidência da República, 1988. Disponível em: 
http://www.planalto.gov.br/ccivil_03/constituicao/constituicao.htm. Acesso em: 24 abr. 2020.

CERDA, Arlen. Aborto en Nicaragua: 12 años de lucha por el derecho a decidir. Confidencial, [S. I.], 26 de novembro de 2018. Disponível em: https://confidencial.com.ni/aborto-en-nicaragua-12-anos-de-lucha-por-el-derecho-adecidir/. Acesso em: 15 set. 2019.

CNBB. Papa Francisco, no encontro "sim à vida": "o aborto nunca é a resposta ideal". CNBB, [S. I.], 28 de maio de 2019. Disponível em: http://www.cnbb.org.br/oaborto-nunca-e-a-resposta-ideal-que-as-mulheres-e-as-familias-buscam-disse-papafrancisco-durante-encontro-sim-a-vida-no-vaticano. Acesso em: 21 out. 2019.

GALEOTTI, Giulia. História do aborto. Coimbra: Edições 70, 2007.

HÖBENREICH, E. Envenenamento e uso indevido de remédios no direito romano. Revista da Faculdade de Direito Universidade de São Paulo, São Paulo, v. 98, p. 23-42, 2003. Disponível em: http://www.revistas.usp.br/rfdusp/article/view/67578/70188. Acesso em: 08 fev. 2019.

HUMAN RIGHTS WATCH. "Es tu decisión, es tu vida": la criminalización total del aborto en la República Dominicana. Human Rights Watch, [S. I.], 19 de novembro de 2018. Disponível em: https://www.hrw.org/es/report/2018/11/19/es-tu-decisiones-tu-vida/la-criminalizacion-total-del-aborto-en-la-republica. Acesso em: 11 out. 2019.

JACOBSEN, Eneida. A história do aborto. Protestantismo em Revista, São Leopoldo, RS, v. 18, p. 102-104, jan./abr. 2009. Disponível em: http://periodicos.est.edu.br/index.php/nepp/article/view/2039. Acesso em: 08 fev. 2019.

LIMA, Maria Cristina Dias de; LAROCCA, Liliana Muller; NASCIMENTO, Dênis José. Abortamento legal após estupro: histórias reais, diálogos necessários. Saúde Debate, Rio de Janeiro, v. 43, n. 121, p. 417-428, abr./jun. 2019.

LOOMIS, W. F. Life as it is: biology for the public sphere. Berkeley, CA: University of California Press, 2008.

MARQUES, Myriam Silva; BASTOS, Marisa Antonini Ribeiro. Aborto provocado como objeto de estudo em antropologia da saúde. REME Revista Mineira de Enfermagem, Belo Horizonte, v. 2, n. 2, p. 57-61, jul./dez. 1998.

MATIELO, Fabrício Zamprogna. Aborto e o direito penal. 3. ed. Porto Alegre: Sagra-DC Luzzatto Editores, 1996.

MORI, Maurizio. A moralidade do aborto. Brasília: UnB, 1997. 
NAÇÕES UNIDAS BRASIL. Especialistas da ONU pedem fim da criminalização do aborto em todo o mundo. Nações Unidas Brasil, [S. I.], 28 setembro 2018. Disponível em: https://brasil.un.org/pt-br/81163-especialistas-da-onu-pedem-fim-dacriminalizacao-do-aborto-em-todo-o-mundo. Acesso em: 11 out. 2019.

NAÇÕES UNIDAS BRASIL. OMS: proibição não reduz número de abortos e aumenta procedimentos inseguros. Nações Unidas Brasil, [S. I.], 28 setembro 2017. Disponível em: https://brasil.un.org/pt-br/77739-oms-proibicao-nao-reduz-numerode-abortos-e-aumenta-procedimentos-inseguros. Acesso em: 11 out. 2019.

REBOUÇAS, Melina Séfora Souza. 0 aborto provocado como uma possibilidade na existência da mulher: reflexões fenomenológico-existenciais. 2010. Dissertação (Mestrado em Psicologia) - Centro de Ciências Humanas, Letras e Artes, Programa de Pós-Graduação em Psicologia, Universidade Federal do Rio Grande do Norte, Natal, 2010.

ROSAS, Erika Guevara. El Salvador e "las 17". Anistia Internacional Brasil, [S. I.], 17 de março de 2015. Disponível em: https://anistia.org.br/el-salvador-e-las-17/. Acesso em: 11 out. 2019.

SÁ, André Beltrão Gadelha de. Evolução histórica do aborto. Conteúdo Jurídico, Brasília, DF, 30 ago. 2016. Disponível em:

http://www.conteudojuridico.com.br/consulta/Artigos/47418/evolucao-historica-doaborto. Acesso em: 08 fev. 2019.

SCHOR, N.; ALVARENGA, A. T. O aborto: um resgate histórico e outros dados. Revista Brasileira de Crescimento e Desenvolvimento Humano, São Paulo, v. 4, n. 2, p. 12-17, 1994.

SEGRE, Marco. A propósito da utilização de células-tronco embrionárias. Estudos Avançados, São Paulo, v. 18, n. 51, p. 257-262, 2004.

SILVA, Bruno Martins da Costa. Da normatização do aborto e suas externalidades. Direito \& Justiça, Porto Alegre, v. 42, n. 2, p. 300-323, jul./dez. 2000. Disponível em: http://revistaseletronicas.pucrs.br/ojs/index.php/fadir/article/view/32833. Acesso em: 20 fev. 2019.

TECEDEIRO, Helena. Malta é cada vez mais o bastião antiaborto na União Europeia. Diário de Notícias, [S. I.], 28 de maio de 2018. Disponível em: https://www.dn.pt/mundo/malta-e-cada-vez-mais-o-bastiao-antiaborto-na-uniaoeuropeia-9384110.html. Acesso em: 29 out. 2019.

TORRES, José Henrique Rodrigues. Aborto e legislação comparada. Ciência e Cultura, São Paulo, v. 64, n. 2, p. 40-44, abr./jun. 2012. Disponível em: http://cienciaecultura.bvs.br/scielo.php?script=sci_arttext\&pid=S000967252012000200017. Acesso em: 20 fev. 2019. 